\title{
Use of a Single Ventilator to Support 4 Patients: Laboratory Evaluation of a Limited Concept
}

\author{
Richard D Branson MSc RRT FAARC, Thomas C Blakeman MSc RRT, \\ Bryce RH Robinson MD, and Jay A Johannigman MD
}

\begin{abstract}
INTRODUCTION: A mass-casualty respiratory failure event where patients exceed available ventilators has spurred several proposed solutions. One proposal is use of a single ventilator to support 4 patients. METHODS: A ventilator was modified to allow attachment of 4 circuits. Each circuit was connected to one chamber of 2 dual-chambered, test lungs. The ventilator was set at a tidal volume $\left(V_{T}\right)$ of $2.0 \mathrm{~L}$, respiratory frequency of $10 \mathrm{breaths} / \mathrm{min}$, and PEEP of $5 \mathrm{~cm} \mathrm{H}_{2} \mathrm{O}$. Tests were repeated with pressure targeted breaths at $15 \mathrm{~cm} \mathrm{H}_{2} \mathrm{O}$. Airway pressure, volume, and flow were measured at each chamber. The test lungs were set to simulate 4 patients using combinations of resistance ( $R$ ) and compliance $(C)$. These included equivalent $C$ and $R$, constant $R$ and variable $C$, constant $C$ and variable $R$, and variable $C$ and variable $R$. Results. When $R$ and $C$ were equivalent the $V_{T}$ distributed to each chamber of the test lung was similar during both volume (range 428 $442 \mathrm{~mL}$ ) and pressure (range 528-544 $\mathrm{mL}$ ) breaths. Changing $C$ while $R$ was constant resulted in large variations in delivered $V_{T}$ (volume range $257-621 \mathrm{~mL}$, pressure range 320-762 mL). Changing $R$ while $C$ was constant resulted in a smaller variation in $V_{T}$ (volume range $418-460 \mathrm{~mL}$, pressure range 502-554 $\mathrm{mL}$ ) compared to only $C$ changes. When $R$ and $C$ were both varied, the range of delivered $V_{T}$ in both volume $(336-517 \mathrm{~mL}$ ) and pressure $(417-676 \mathrm{~mL})$ breaths was greater, compared to only $R$ changes. CONCLUSIONS: Using a single ventilator to support 4 patients is an attractive concept; however, the $V_{T}$ cannot be controlled for each subject and $V_{T}$ disparity is proportional to the variability in compliance. Along with other practical limitations, these findings cannot support the use of this concept for mass-casualty respiratory failure. Key words: mass-casualty; respiratory failure; mechanical ventilation. [Respir Care 2012;57(3):399-403. (c) 2012 Daedalus Enterprises]
\end{abstract}

\section{Introduction}

The threat of pandemic respiratory illness and masscasualty respiratory failure has resulted in a number of potential solutions, ranging from ventilator stockpiling to triage. ${ }^{1-4} \mathrm{We}$ and others have suggested characteristics for ventilators purchased for stockpiling, which include the

The authors are affiliated with the Division of Trauma and Critical Care, Department of Surgery, University of Cincinnati, Cincinnati, Ohio.

Mr Branson presented a version of this paper at the Annual Congress of the Society of Critical Medicine, held January 9-13, 2010, in Miami, Florida.

Mr Branson has disclosed relationships with Ikaria, General Electric, Covidien, Hamilton Medical, and Breathe Technologies. The other authors have disclosed no conflicts of interest. ability to support patients with acute respiratory distress syndrome (ARDS). The most recent novel H1N1 flu, emerging from Mexico in early 2010 and resulting in frequent severe ARDS, validates this recommendation.

In 2007, Neyman and Irvin reported the use of one ventilator to support 4 passive, rubber test lungs. ${ }^{5}$ This paper did not subject the observations to any scientific measurement or critical evaluation. Paladino and colleagues followed that observation with an animal study using 4

\footnotetext{
Correspondence: Richard Branson MSc RRT FAARC, Division of Trauma and Critical Care, Department of Surgery, University of Cincinnati, 231 Albert Sabin Way, Cincinnati OH 45267-0558. E-mail: richard.branson@uc.edu.
}

DOI: $10.4187 /$ respcare. 01236 


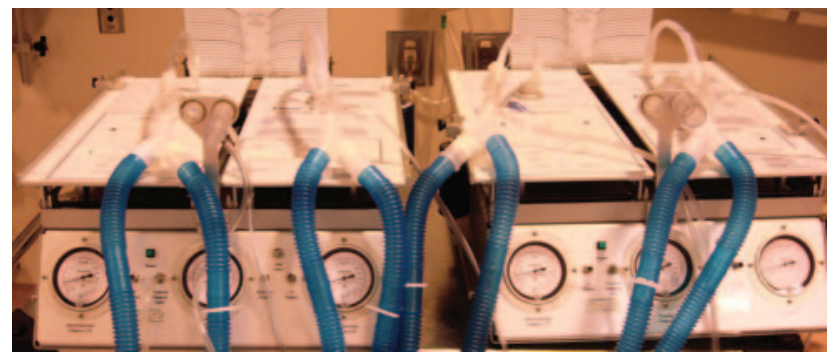

Fig. 1. Photograph of the 2 test lungs simulating 4 patients and the 4 individual circuits. Fixed orifice pneumotachographs are connected between the circuit outlet and the test lung.

sheep with normal lungs. ${ }^{6}$ In this trial there were significant differences in gas exchange, requiring frequent blood gas evaluations and manipulation of animal position to maintain homeostasis. While each of these investigations have been criticized at length, ${ }^{7,8}$ support for this idea continues. ${ }^{9}$

We designed a lung model investigation of the concept of one ventilator for 4 patients, using mechanical lung analogues at varying levels of airway resistance and lung compliance. The goal of the trial was to determine the distribution of tidal volume $\left(\mathrm{V}_{\mathrm{T}}\right)$ and end-expiratory lung volume in identical and varying "patient" characteristics.

\section{Methods}

A Puritan-Bennett 840 ventilator was set up according to manufacturer specifications. A modified ventilator circuit, as described by Neyman and Irvin, was connected to the ventilator outlet. ${ }^{5}$ The outlet of the ventilator led to a T-piece that split the outlet in 2 and then into 2 additional T-pieces, thus creating 4 outlets for gas flow (Fig. 1). At each outlet a standard 60 -inch disposable ventilator circuit was connected. The expiratory limb had the identical arrangement of T-pieces to allow a single flow of gas to the expiratory valve. The standard pre-use procedure was performed and all tests passed. The circuit compliance was measured at $9 \mathrm{~mL} / \mathrm{cm} \mathrm{H}_{2} \mathrm{O}$. No humidification was used during the experiment. The ventilator was set at a $\mathrm{V}_{\mathrm{T}}$ of $2.0 \mathrm{~L}$ in the continuous mandatory ventilation mode. The respiratory rate was set at 10 breaths/min and the inspiratory time was $2.0 \mathrm{~s}$, creating an inspiratory-expiratory ratio of $1: 2$. PEEP was $5 \mathrm{~cm} \mathrm{H}_{2} \mathrm{O}$ and the $\mathrm{F}_{\mathrm{IO}_{2}}$ was 0.21 . The breath type was then changed to pressure targeted, at a set pressure of $15 \mathrm{~cm} \mathrm{H}_{2} \mathrm{O}$, with all other settings remaining constant.

Each circuit was connected to a single chamber of 2 separate dual-chamber test lungs (Training and Test Lung, Michigan Instruments, Grand Rapids, Michigan). Compliance and resistance was varied according to Table 1 . In this simulation we used endotracheal tubes (ETTs) of varying sizes (6.5-8.5 $\mathrm{mm}$ inner diameter) to control airway

\section{QUICK LOOK}

\section{Current knowledge}

Mass-casualty respiratory failure requires innovative solutions to meet demands of a surge of critically ill patients requiring ventilatory support. The use of a single ventilator to support more than 1 patient has been proposed as a solution.

\section{What this paper contributes to our knowledge}

The use of a single ventilator to ventilate more than 1 patient results in wide variations in tidal volume delivery. Variable compliance contributes to the inequity in tidal volume delivery more than resistance; pressure control ventilation exacerbates the disparity compared to volume control ventilation.

resistance. These ETTs were connected directly to the inlet of the test lung. There were 4 simulated conditions. In condition 1, ETT size and set lung compliance were equivalent for all 4 lungs. In condition 2, ETT sizes were fixed and compliance was varied. In condition 3, ETT sizes were varied and lung compliance was held fixed. In the final simulation both ETT size and lung compliance were varied.

Between each ventilator circuit and the ETT we placed a fixed orifice pneumotachograph that was connected to a $\mathrm{COSMO}+$ respiratory monitor (Novametrix, Wallingford, Connecticut). Each monitor was connected to a portable computer for continuous recording of airway pressure, volume, and flow. The data were displayed using Analysis ${ }^{+}$ software (Novametrix, Wallingford, Connecticut) and downloaded to an Excel (Microsoft, Redmond, Washington) spreadsheet for later analysis. We also determined the test lung functional residual capacity (FRC) by monitoring the expired $\mathrm{V}_{\mathrm{T}}$ when PEEP was turned from $5 \mathrm{~cm} \mathrm{H}_{2} \mathrm{O}$ to $0 \mathrm{~cm} \mathrm{H}_{2} \mathrm{O}$. The $\mathrm{V}_{\mathrm{T}}$ reported represent the mean $\pm \mathrm{SD}$ of 10 breaths, and the FRC measurements represent the mean \pm SD of 3 measurements.

\section{Results}

The delivered $\mathrm{V}_{\mathrm{T}}$ to each simulated patient under the 4 conditions of compliance and ETT size are shown in Figure 2 (volume targeted) and Figure 3 (pressure targeted). At each compliance and ETT size a pressure-targeted breath of $15 \mathrm{~cm} \mathrm{H}_{2} \mathrm{O}$ resulted in a larger $\mathrm{V}_{\mathrm{T}}$ to each of the 4 simulated patients, compared to a set $\mathrm{V}_{\mathrm{T}}$ of $2.0 \mathrm{~L}$. When the compliance and ETT size were varied, the differences in delivered $\mathrm{V}_{\mathrm{T}}$ to each simulated patient were exacerbated by the use of pressure targeted breaths. FRC measure- 
Table 1. Four Simulations Used for Evaluating One Ventilator Supporting 4 Patients

\begin{tabular}{lccc}
\hline \hline \multicolumn{1}{c}{ Simulation } & $\begin{array}{c}\text { Simulated } \\
\text { Patient } \\
\text { Number }\end{array}$ & $\begin{array}{c}\text { ETT Inner } \\
\text { Diameter } \\
(\mathrm{mm})\end{array}$ & $\begin{array}{c}\text { Compliance } \\
\left(\mathrm{L} / \mathrm{cm} \mathrm{H}_{2} \mathrm{O}\right)\end{array}$ \\
\hline Identical test-lung compliance and & 1 & 8.0 & 0.05 \\
ETT resistance & 2 & 8.0 & 0.05 \\
& 3 & 8.0 & 0.05 \\
Identical ETT resistance variable & 4 & 8.0 & 0.05 \\
test-lung compliance & 1 & 8.0 & 0.03 \\
& 2 & 8.0 & 0.04 \\
Identical test-lung compliance & 3 & 8.0 & 0.06 \\
variable ETT resistance & 4 & 8.0 & 0.07 \\
& 2 & 8.0 & 0.05 \\
& 3 & 7.0 & 0.05 \\
Variable test-lung compliance and & 1 & 8.5 & 0.05 \\
ETT resistance & 2 & 6.5 & 0.05 \\
& 3 & 8.0 & 0.05 \\
& 4 & 6.5 & 0.06 \\
& & & 0.04 \\
& & &
\end{tabular}

$\overline{\mathrm{ETT}}=$ endotracheal tube

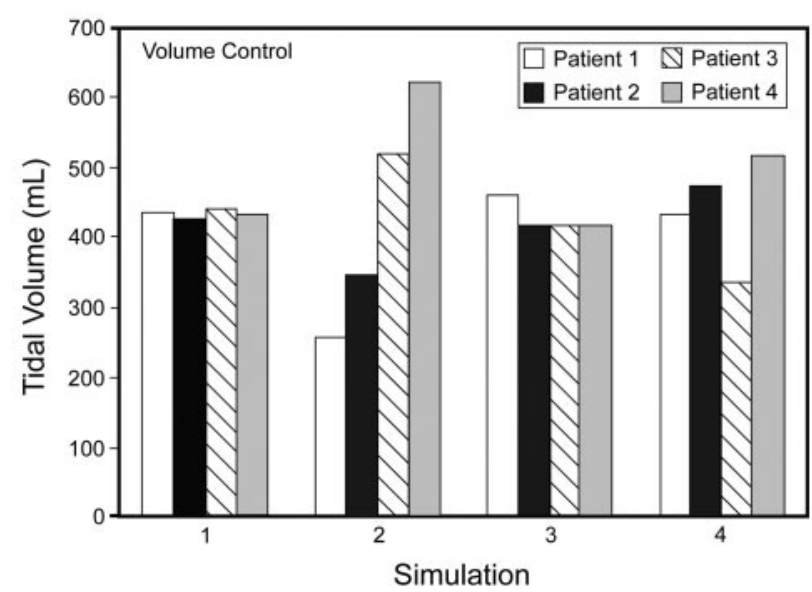

Fig. 2. Distribution of tidal volume during the 4 simulations using volume targeted ventilation.

ments were similar between the breath types within each simulation (Table 2).

In volume targeted ventilation the peak inspiratory pressure was $14 \mathrm{~cm} \mathrm{H}_{2} \mathrm{O}$ for simulations 1,2 , and 4, with the peak inspiratory pressure in simulation 3 being $15 \mathrm{~cm} \mathrm{H}_{2} \mathrm{O}$. In pressure targeted ventilation the peak inspiratory pressure was $16 \mathrm{~cm} \mathrm{H}_{2} \mathrm{O}$ in each simulation, except in simulation 2 with patient 4 , which had peak inspiratory pressures of $15 \mathrm{~cm} \mathrm{H}_{2} \mathrm{O}$.

Changes in compliance alone resulted in larger differences in delivered $\mathrm{V}_{\mathrm{T}}$ between "patients" than did changes in ETT size alone (see Figs. 2 and 3). The range of deliv-

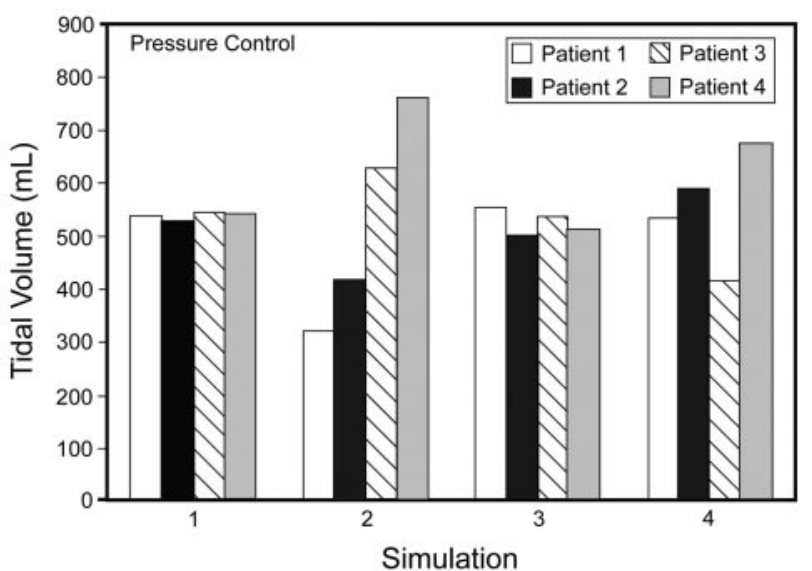

Fig. 3. Distribution of tidal volume during the 4 simulations using pressure targeted ventilation.

ered $\mathrm{V}_{\mathrm{T}}$ in volume targeted ventilation was narrow under equivalent compliance and ETT size (simulation 1: 428 $442 \mathrm{~mL}$ ) and widest when compliance alone was varied (simulation 2: 257-621 mL). $\mathrm{V}_{\mathrm{T}}$ variability with changes in ETT size alone was greater than simulation 1 but much smaller than simulation $2(418-460 \mathrm{~mL})$. Varying both compliance and ETT size predictably resulted in a wide variation in delivered $\mathrm{V}_{\mathrm{T}}(336-517 \mathrm{~mL})$. Similar variability was seen under the 4 simulations with the use of pressure targeted ventilation.

\section{Discussion}

A potential ventilator shortage during a mass-casualty respiratory failure event has resulted in a number of real and potential remedies. ${ }^{1-6}$ While these remedies continue to be pursued, no mass-casualty respiratory failure event with too many patients and too few ventilators has thus far been encountered. The idea of using one ventilator to provide ventilation for more than one patient has been discussed by others. ${ }^{10}$ An initial report from 1994 attempted to use a single ventilator to care for 2 patients, but allowed completely separate circuits and independent adjustment of PEEP. This system would be superior to the one suggested by Neyman and Irvin. ${ }^{6}$

The major findings of our study are that, while equivalent ventilation can be provided when compliance and ETT size are identical, differences in compliance can result in a wide variation in delivered $\mathrm{V}_{\mathrm{T}}$, and since PEEP is constant, FRC is variable as well. Changes in ETT size alone resulted in variable $\mathrm{V}_{\mathrm{T}}$, but to a lesser extent, compared to compliance changes. We also found that when pressure targeted ventilation was used, the discrepancies in delivered $\mathrm{V}_{\mathrm{T}}$ between simulated patients was exacerbated.

The results of this study were anticipated based on ventilator operation and distribution of ventilation based on 
Table 2. Difference in Mean Tidal Volume and Mean Functional Residual Capacity Between Volume Control and Pressure Control Ventilation in the 4 Different Simulated Patients

\begin{tabular}{|c|c|c|c|c|c|c|c|}
\hline \multirow[t]{2}{*}{ Simulation } & \multirow{2}{*}{$\begin{array}{l}\text { Simulated } \\
\text { Patient } \\
\text { Number }\end{array}$} & \multicolumn{2}{|c|}{ Tidal Volume $(\mathrm{mL})$} & \multirow{2}{*}{$\begin{array}{l}\% \text { Difference } \\
\text { Volume vs } \\
\text { Pressure }\end{array}$} & \multicolumn{2}{|c|}{$\begin{array}{c}\text { Functional Residual } \\
\text { Capacity }(\mathrm{mL})\end{array}$} & \multirow{2}{*}{$\begin{array}{l}\text { \% Difference } \\
\text { Volume vs } \\
\text { Pressure }\end{array}$} \\
\hline & & Volume & Pressure & & Volume & Pressure & \\
\hline \multirow[t]{4}{*}{ Constant endotracheal tube size and compliance } & 1 & 436 & 539 & 23.6 & 236 & 226 & -4.3 \\
\hline & 2 & 428 & 528 & 23.3 & 228 & 230 & 0.08 \\
\hline & 3 & 442 & 546 & 23.5 & 245 & 256 & 4.5 \\
\hline & 4 & 436 & 544 & 24.7 & 239 & 258 & 7.9 \\
\hline \multirow[t]{4}{*}{ Constant endotracheal tube size and variable compliance } & 1 & 257 & 320 & 24.5 & 152 & 144 & 7.9 \\
\hline & 2 & 346 & 419 & 21.0 & 193 & 187 & -3.2 \\
\hline & 3 & 520 & 629 & 20.9 & 318 & 304 & -4.4 \\
\hline & 4 & 621 & 762 & 22.7 & 374 & 372 & -0.06 \\
\hline \multirow[t]{4}{*}{ Variable endotracheal tube size and constant compliance } & 1 & 460 & 554 & 20.4 & 257 & 268 & 4.2 \\
\hline & 2 & 418 & 502 & 20.0 & 264 & 271 & 2.6 \\
\hline & 3 & 418 & 537 & 28.4 & 253 & 261 & 3.1 \\
\hline & 4 & 419 & 515 & 22.9 & 269 & 277 & 2.9 \\
\hline \multirow[t]{4}{*}{ Variable endotracheal tube size and variable compliance } & 1 & 433 & 535 & 23.6 & 244 & 245 & 0.04 \\
\hline & 2 & 473 & 591 & 24.9 & 288 & 306 & 6.25 \\
\hline & 3 & 336 & 417 & 24.1 & 207 & 209 & 0.01 \\
\hline & 4 & 517 & 676 & 30.1 & 363 & 372 & 0.08 \\
\hline
\end{tabular}

regional time constants. However, given the original description that did not provide any scientific measurements ${ }^{5}$ and the follow-on animal trial, ${ }^{6}$ this trial is justified to highlight limitations of a single ventilator for 4 patients concept.

The animal trial by Paladino et al used 4 normal, anesthetized sheep and observed marked differences in gas exchange, despite the absence of lung pathology. Both relative hypoxemia and hypercarbia were observed. Arterial blood gas analysis was obtained every hour and animals were re-positioned to provide more uniform ventilation. Inability to provide similar ventilation in 4 normal, anesthetized animals, combined with our findings and the heterogeneity of lung mechanics in patients with acute respiratory failure, would provide little support for the success of this technique in patients. This is further complicated by the importance of delivering $\mathrm{V}_{\mathrm{T}}$ based on patient height. Previous descriptions assume that all patients are the same height. Even if $\mathrm{V}_{\mathrm{T}}$ were equally distributed, this may result in inappropriate volume delivery to some patients. This study highlights another glaring limitation of this technique: the monitoring of airway pressure, volume, and flow represents the group, not individual subjects. Therefore, changes in individual subjects can be identified only by external monitoring, including pulse oximetry, stand-alone airway carbon dioxide analyzers, or invasive measurements.

Previously, investigators have designed techniques for ventilators to provide a constant respiratory rate at variable $\mathrm{V}_{\mathrm{T}}$ and PEEP for independent ventilation of the lungs in unilateral pulmonary pathology. ${ }^{11-13}$ Such techniques use a separate circuit for both lungs and allow for titration of ventilatory parameters to the individual pathology. Each of these techniques would allow for greater flexibility and reduced risk of cross contamination than the "one ventilator for 4 patients" concept.

Limitations of the concept are numerous. They include inability to monitor subjects individually; inability to provide separate inspired oxygen, $\mathrm{V}_{\mathrm{T}}$, and PEEP based on pulmonary pathology; risk of cross contamination in febrile respiratory illness; and the need for staff training in a new methodology. We did not evaluate triggering formally, but noted that application of negative pressure to one of the 4 "patients" resulted in a reduction in the resting FRC of the other 3 "patients" without triggering the ventilator, suggesting sharing of gas from the circuit, thus cross contamination could be a major concern. In a scenario where 4 patients share a ventilator, the respiratory rate is determined by the patient with the greatest demand.

The study has a number of limitations. We tested only mandatory breaths in a single mode. We did not evaluate the effects of ventilator triggering, nor did we assess the issue of infection control, which is of major concern with this technique. We did not alter respiratory rate or inspiratory-expiratory ratio. We do, however, believe that this study demonstrates the multitude of limitations of using one ventilator to ventilate 4 patients simultaneously.

\section{Conclusions}

In conclusion, in a lung model evaluation of using a single ventilator to provide ventilatory support for 4 sub- 
jects, the data suggest that this technique has important hurdles to overcome. At present, the use of this technique should be avoided, given the potential hazardous and untoward complications.

\section{ACKNOWLEDGMENTS}

The authors are grateful to Robert Campbell RRT FAARC for providing the additional COSMO+ monitors and for his technical expertise.

\section{REFERENCES}

1. Rubinson L, Branson RD, Pesick N, Talmor D. Positive pressure ventilation equipment for mass casualty respiratory failure. Biosecur Bioterror 2006;4(2):1-12.

2. Daugherty EL, Branson RD, Rubinson L. Mass casualty respiratory failure. Curr Opin Crit Care 2007;13(1):51-56.

3. Rubinson L, Hick JL, Curits JR, Branson RD, Burns S, Christian $\mathrm{MD}$, et al; Task Force for Mass Critical Care. Definitive care for the critically ill during a disaster: medical resources for surge capacity from a Task Force for Mass Critical Care summit meeting, January 26-27, 2007, Chicago, IL. Chest 2008;133(5 Suppl):32S-50S.

4. Branson RD, Johannigman JA, Daugherty EL, Rubinson L. Surge capacity mechanical ventilation. Respir Care 2008;53(1):78-90.
5. Neyman $G$ and Irvin CB. A single ventilator for multiple simulated patients to meet disaster surge. Acad Emerg Med 2006; 13(11):1246-1249

6. Paladino L, Silverberg M, Charchaflieh JG, Eason JK, Wright BJ, Palamidessi N, et al. Increasing ventilator surge capacity in disasters: ventilation of four adult-human-sized sheep on a single ventilator with a modified circuit. Resuscitation 2008;77(1):121-126.

7. Branson RD, Rubinson L. A single ventilator for multiple simulated patients to meet disaster surge. Acad Emerg Med 2006;13(12): 1352-1353.

8. Branson RD, Rubinson L. One ventilator, multiple patients-what the data really support (letter). Resuscitation 2008;79(1):171-172.

9. Paladino L. One ventilator, multiple patients-what the data really support (author reply). Resuscitation 2008;79(1):172-173.

10. Sommer DD, Fisher JA, Ramcharan V, Marshall S, Vidic DM. Improvised automatic lung ventilation for unanticipated emergencies. Crit Care Med 1994;22(5):705-709.

11. Powner DJ, Eross B, Grenvik A. Differential lung ventilation with PEEP in the treatment of unilateral pneumonia Crit Care Med 1977; 5(1):170-172.

12. Cavanilles JM, Garrigosa F, Prieto C Oncins JR. A selective ventilation distribution circuit (S.V.D.C) Intensive Care Med 1979;5(1): 95-98.

13. Gallagher TJ, Banner MJ, Smith RA. A simplified method of independent lung ventilation. Crit Care Med 1980;8(2):396-399. 